УдК 81`42

НЕМЫКА Анна Анатольевна

Кубанский государственный университет

г. Краснодар, Россия

annemyka@yandex.ru

СЫТИНА Алла Викторовна

Кубанский государственный университет

г. Краснодар, Россия

МЕЖДИСЦИПЛИНАРНОСТЬ И
ПОЛИФУНКЦИОНАЛЬНОСТЬ В СИСТЕМЕ
ПОНЯТИЙ СОВРЕМЕННОЙ НАУКИ (НА
МАТЕРИАЛЕ ТЕРМИНОВ
СОЦИОЛИНГВИСТИКИ, СОЦИОЛОГИИ И
ЛИНГВИСТИКИ)

Статья посвящена изучению особенностей реализации важных свойств междисциплинарности и полифункциональности в рамках современной научной понятийной парадигмы. Исследование проводится на материале единиц, функционирующих преимущественно в рамках терминосистем социолингвистики, социологии и лингвистики Актуальность темы обусловлена недостаточной разработанностью в современной науке вопросов системного исследования междисциплинарной интегративной специфики терминологического узуса. В настоящий момент накоплен богатый опыт описания языков разных наук, в том числе и новых, формирующих свою понятийную парадигму. Однако исследователи до сих пор не обращали достаточного внимания на такие аспекты терминосистемы, как ее узуальная и дефиниционная специфика в сфере существования новых научных направлений. Проблема состоит и в том, что современные понятийные системы социолингвистики, социологии и лингвистики характеризуются рядом специфических черт, которые проявляются в области их семантических связей и функциональных черт. И если по отношению ко многим терминам в этом плане уже созданы научные исследования, то по отношению к специальным единицам указанных областей таких исследований существует еще недостаточное количество для того, чтобы проблема считалась разрешенной, аргументированной и доказанной. В статье приводятся мнения ученых, опирающихся на положения современной методологии и терминологической теории и практики. На основании такого изучения материала делаются выводы об исследуемых конститутивных параметрах терминологического дискурса.
DOI: $10.17748 / 2075-9908-2018-10-3 / 2-120-124$

Anna A. NEMYKA

Kuban State University

Krasnodar, Russia

annemyka@yandex.ru

Alla V. SYTINA

Kuban State University

Krasnodar, Russia

\section{INTERDISCIPLINARITY AND \\ POLYFUNCTIONALITY IN THE SYSTEM OF CONCEPTS OF MODERN SCIENCE (BASED ON THE TERMS OF SOCIOLINGUISTICS, SOCIOLOGY, AND \\ LINGUISTICS)}

The article is devoted to the study of the peculiarities of realization of important properties of interdisciplinarity and polyfunctionality within the framework of the modern scientific conceptual paradigm. The study is based on the material of units functioning mainly within the term systems of sociolinguistics, sociology and linguistics. The relevance of the topic is due to the lack of development in modern science of the issues of systematic research of interdisciplinary integrative specificity of terminological usage. At the moment, we have accumulated a rich experience of describing languages of different Sciences, including new ones, which form their conceptual paradigm. However, researchers have so far not paid enough attention to such aspects of the terminology as its usual and specific features in the field of the existence of new scientific directions. The problem also lies in the fact that modern conceptual systems of sociolinguistics, sociology and linguistics are characterized by a number of specific features that manifest themselves in the field of their semantic connections and functional features. And if scientific research has already been created in relation to many terms, then in relation to the special units of these areas of such studies there is still not enough quantity for the problem to be considered resolved, reasoned and proven. The article cites the opinions of scientists, based on the provisions of modern methodology and terminology theory and practice. Based on such a study of the material, conclusions are drawn about the constitutive parameters of the terminological discourse under investigation.

Ключевые слова: языковая личность, аксиология, Кеywords: term, interdisciplinarity, sociolinguisкоммуникативная прагматика, метаязык, термин, tics, sociology, polyfunctionality, anthropocenхудожественный текст trism, terminological discourse

Существенной чертой формирующихся сфер знания, по мнению ученых, специализирующихся на изучении современной методологии, можно считать междисциплинарность. Это в достаточной степени реализовано в таких науках, как социология, философия, лингвистика, психология [1, с. 5]. 
В современной научной парадигме активно развиваются области, в наименования которых включены элементы лингвистика или лингво- в сочетании с названиями смежных наук: социолингвистика, психолингвистика, антрополингвистика и др.

Однако в современных междисциплинарных трудах заметны когнитивные и логические противоречия в излагаемых теориях [2, с. 3]. Следует отметить как важный методологический принцип, связывающий лингвистику со смежными науками, в том числе с социологией и социолингвистикой, антропоцентризм. Его основа заключается в том, что роль личности, всего, что связано с ее жизнедеятельностью, является определяющей и конституирующей в выборе научных объектов для исследования. Антропоцентрический подход репрезентирует человека в качестве ядра когнитивно-исследовательской парадигмы [3, с. 165].

Следует также учитывать объемность функционала междисциплинарного термина «антропоцентризм» в зависимости от сферы использования. Например:

1. Антропоцентризм в философии и социологии - научное направление, определяющее человека как центральную часть Вселенной, а также цель всех событий; в философской научной теории он считается учением, противоположным космоцентризму [4].

2. В рамках современной языковедческой науки антропоцентризм до сих пор не имеет единого определения. Систематически предпринимаются попытки связать его когнитивистикой.

Следует отметить, что ядром в континууме языкознания, причем в любой его области, будет являться язык как таковой в качестве семиотической системы. В связи с этим в современной науке не всегда верно используется понятие «антропоцентризм» применительно к социолингвистическим объектам. Ученым необходимо прежде всего учитывать лингвоцентрический фактор, а не языковой антропоцентризм.

Понимание антропоцентризма, трактуемого преимущественно как принцип научной методологии, соотносится с постструктуралистской научной теорией и анализом проблематики интегративных исследований в рамках современной научной теории и практики. Это находит последовательное отражение в различных научных областях. Например, антрополингвистика, которая занимается рассмотрением вопросов эволюции мышления индивида в тесной связи с языковыми изменениями, является разделом прикладного языкознания, а не теоретического, что весьма существенно при формировании понятийного корпуса социолингвистики [5].

В современном научном дискурсе зачастую можно наблюдать использование терминологического сочетания «антропоцентрическая парадигма», при котором не уделяется должного внимания дефиниционной специфике интегративного понятия антропоцентризма. Следовательно, становится очевидным тот факт, что терминология существенно затрудняет и усложняет интегративные научные разработки, проводимые на стыке различных дисциплин, так как специальные единицы, заимствованные из других сфер, в новом дефинитивном дискурсе трактуются не вполне точно [1, c. 114]. Например, в психологии и социологии под языком для специальных целей понимается языковая структура, «скрывающая истинный смысл выражаемого обычным языком» [6, с. 8]. Активное развитие теории и практики интегративных исследований, в том числе на стыке социологии и лингвистики, предопределяет в перспективе необходимость выпуска лексикографических изданий, репрезентирующих параллельные дефиниции омонимичных терминов.

Учет фактора общей системности терминологии, а также взаимосвязанное представление научного предмета и объекта является обязательным условием процесса создания новых терминоединиц. В рамках современной научной парадигмы можно отметить использование без достаточной семантизации некоторых новых терминоединиц, репрезентирующих абстрактные понятия. Между тем подобные термины нуждаются в максимально четком определении в научном дискурсе, так как носят формирующийся характер.

В современном научном методологическом дискурсе к специальной лексике относят слова и словосочетания, которые обозначают предметы и понятия, относящиеся к различным сферам человеческой деятельности. В нее включают термины, профессиона- 
лизмы и профессиональные жаргонизмы, которые не являются широко распространенными.

Также весьма существенной является теоретическая проблема, касающаяся самого терминологического значения и аспекта его роли, ее значимости в смысловой схеме парадигмы компонентов естественного языка. Наиболее рациональным способом решения этого вопроса является детальное исследование статей толкового и терминологического словарей. В данном случае наиболее показательно сопоставление специальных единиц новой (например, социолингвистической) и уже вполне сформировавшейся (например, социологической) областей знания. Системный анализ соотнесенности вариантных и инвариантных терминов, репрезентирующих какую-либо одну научную область с включением единиц возникающих в ее рамках разделов, является, на наш взгляд, наиболее эффективным. Таким образом представляется возможным исследование возникновения понятий новых областей науки на основе переноса уже активно функционирующих обозначений на новые компоненты системы.

При анализе языка для специальных целей следует учитывать тот факт, что его единицы координируются с терминологией на основе гипонимических и гиперонимических связей. Таким образом, наиболее устоявшееся определение специальной лексики содержит в основе слова и сочетания слов, иллюстрирующие те или иные области человеческой деятельности и номинирующие соответствующие понятия. Важно и то, что они не относятся к общеупотребительным единицам. В специальную лексику входят термины и профессионализмы. Между включаемыми в парадигму языка для специальных целей профессионализмами и терминоэлементами существует обусловленное структурными причинами разграничение. Важным и основным отличием стандартной терминоединицы от специальной лексической единицы является обязательная четкая дефинированность, функциональная закрепленность за соответствующим стилевым дискурсом, определенная устойчивость структурно-компонентного состава, то есть совокупность функциональных и прагматических факторов.

Особенности репрезентации единиц языка для специальных целей в словарях соответствующего типа напрямую связаны с их спецификой и комплексом условий, учитывающихся при лексикографической характеристике единиц языка в целом. В процессе использования в сфере профессионального общения лексических элементов языка для специальных целей четко осознается потребность кодификации системы терминов. Это во многом обусловлено возможностью терминоединиц использоваться не только в прямом, но и в переносном значении как в рамках одной системы терминов, так и в языке в целом. Указанная особенность способствует возникновению отношений омонимии и многозначности терминов [7, с. 11]. Содержание дефиниции напрямую связано со спецификой структуры словарной статьи, ориентированной на разные группы референтов. Проиллюстрировать данное положение в аспекте динамических процессов современного словаря возможно с помощью исследования вновь возникающих единиц специальной лексики. Лексическая система языка и различные страты специальной лексики в определенной степени охвачены омонимией интегративного характера и полисемией, реализованной внутри системы.

Краткий аналитический обзор статей современных лексикографических источников показывает, что большинство словарей, содержащих общеупотребительную лексику, включает значительное количество лексем для специальных целей, в том числе из актуальных научных сфер - социологической и социолингвистической. Отмеченная особенность связана с полисемантическими и омонимическими возможностями некоторых специальных и общеупотребительных лексических единиц. Еще одной важной понятийной проблемой исследуемой сферы является сложность представления четких и однозначных дефиниций в словарях разного типа. Это во многом связано с тем, что и в пределах 
одного словаря маркеры, которые характеризуют лексику для специальных целей, представлены в следующих вариантах: 1) маркировка общего типа - сnещ.; 2) специальная сфера функционирования - техн., филос., в лингвистике, в логике, в философии, в названиях некоторых естественных наук и т.д. Иногда единица языка для специальных целей характеризуется наличием маркеров книжн. (у терминоединиц) и разг. (у профессионализмов). Можно также отметить следующее: при дефинировании некоторых специальных лексических единиц ученые могут пропустить ссылку на специальный характер семантики компонента [8].

Например, интегративный термин субъект, толкование которого не совпадает в научных областях - философии, логике, социологии, грамматике, правоведении и др., дается в словарных статьях в системе вариантов. Так, в «Словаре русского языка» (1997) не совсем правомерно функционирует между специальными понятиями лексикосемантический вариант «вообще о человеке (разг.)». А в «Словаре иностранных слов» (1990) отсутствует маркер, который бы свидетельствовал об отнесении первого из представленных вариантов лексемы к сфере философии и социологии:

Субъект - 1. Человек как носитель каких-нибудь свойств. С. права (физическое или юридическое лицо как носитель юридических прав и обязанностей; спец.). 2. В философии: познающий и действующий человек. 3. В логике: предмет суждения. 4. В грамматике: семантическая категория со значением производителя действия (СРЯ-90).

Субъект - 1. В философии и социологии: человек, познающий и действующий. 2. Человек как носитель каких-н. свойств (книжн.). С. права (физическое или юридическое лицо; спец.). 3. Вообще о человеке (разг.). 4. В логике: предмет суждения. 5. В грамматике: семантическая категория со значением производителя действия (СРЯ - 97) [9].

Таким образом, ученые, принимающие участие в составлении словарей, в достаточной степени субъективны в вопросах представления научной и языковой картины мира. При дефинировании лексики для специальных целей в словарях различного типа зачастую нарушается принцип логической последовательности расположения материала, не реализованы конститутивные принципы отнесения лексической единицы к специальной лексике, существенную роль играет собственная ассоциативность составителя словаря, его профессиональная компетенция. Следовательно, терминологические работы, в особенности в новых областях знания (в том числе и социолингвистической), должны выполняться учеными коллективно.

\section{БИБЛИОГРАФИЧЕСКИЕ ССЫЛКИ}

1. Тимофеева М.К. Язык с позиций философии, психологии и математики: Учеб. пособ. / М.К. Тимофеева. - М., 2009. - 176 с.

2. Золотова Г.А. Коммуникативная грамматика русского языка / Г.А. Золотова, Н.К. Онипенко, М.Ю. Сидорова. - М., 2004. - 544 с.

3. Угланова И.А. Существует ли мейнстрим в современной лингвистике? / И.А. Угланова // Филологические заметки : Межвуз. сб. науч. тр. - Вып. 4: в 2-х ч. - Пермь; Скопье; Любляна, 2006. - Ч.1. - С. 163-173.

4. Философский энциклопедический словарь [Электронный ресурc]. - URL: http://dic.academic.ru/. - Загл. с экрана.

5. Немыка А.А. Полифункциональность как конститутивное свойство современного термина лингвистики / А.А. Немыка, А.Н. Пешков // Гуманитарные, социально-экономические и общественные науки. - 2014. - № 3. - С. 376-378.

6. Пиз А. Язык разговора / А. Пиз, А. Гарнер. - М., 2002. - 169 с.

7. Парижева М.А. Особенности функционирования лингвистических терминов в профессиональной речи: Дис. ... канд. филол. наук. - Магас, 2005. - 254 с.

8. Немыка А.А. Терминология теории аргументации: когнитивные параметры специального обозначения / А.А. Немыка, А.А. Ушаков // Вестник Российского университета дружбы 
народов, Сер. Русский и иностранные языки и методика их преподавания. - 2012. - № 3. - С. 72-77.

9. Немыка А.А. Метаязык лингвистики: научное и художественное представление: Дис. ... д-ра филол. наук. - М., 2017. - 342 с.

\section{REFERENCES}

1. Timofeeva M.K. Yazyk s pozitsiy filosofii, psikhologii i matematiki : ucheb. posobiye [Language from the standpoint of philosophy, psychology and mathematics: Textbook. Allowance]. M.K. Timofeeva. Moscow, 2009. 176 p.

2. Zolotova G.A. Kommunikativnaya grammatika russkogo yazyka [Communicative grammar of the Russian language]. G.A. Zolotova, N.K. Onipenko, M.Yu. Sidorova. Moscow, 2004. 544 p.

3. Uglanov I.A. Sushchestvuyet li meynstrim v sovremennoy lingvistike? [Is there a mainstream in modern linguistics?]. I.A. Uglanov. Philological notes: intercollegiate. Sat. sci. tr. Vol. 4: in 2 parts. Perm; Skopje; Ljubljana, 2006. Part 1. Pp. 163-173.

4. Philosophical Encyclopedic Dictionary Available at: URL: http://dic.academic.ru/. - Ver. from the screen.

5. Nemyka A.A. Polifunktsional'nost' kak konstitutivnoye svoystvo sovremennogo termina lingvistiki [Polyfunctionality as a Constituent Property of the Modern Term of Linguistics]. A.A. Nemyka, A.N. Peshkov. Humanities, Socio-Economic and Social Sciences. 2014. No. 3. Pp. 376-378.

6. Pease A. Yazyk razgovora [Language of conversation]. A. Pease, A. Garner. Moscow, 2002.169 p.

7. Parizheva M.A. Osobennosti funktsionirovaniya lingvisticheskikh terminov v professional'noy rechi : dis. ... kand. filol. nauk [Features of the functioning of linguistic terms in professional speech: dis. ... cand. philol. sciences]. Magas, 2005. 254 p.

8. Nemyka A.A. Terminologiya teorii argumentatsii: kognitivnyye parametry spetsial'nogo oboznacheniya [Terminology of the theory of argumentation: cognitive parameters of a special notation]. A.A. Nemyka, A.A. Ushakov. Bulletin of the Russian Peoples Friendship University, Ser. Russian and foreign languages and methods of their teaching. 2012. No. 3. Pp. 72-77.

9. Nemyka A.A. [Metayazyk lingvistiki: nauchnoe i hudozhestvennoe predstavlenie : dis. ... doc. filol. nauk [The metalanguage of linguistics: scientific and artistic representation: dis. ... doc. philol. sciences]. Moscow, 2017. 342 p.

\section{Информация об авторах:}

Немыка Анна Анатольевна, доктор филологических наук, доцент, кафедра русского языка как иностранного, Кубанский государственный университет,

г. Краснодар, Россия

annemyka@yandex.ru

Сытина Алла Викторовна, кандидат филологических наук, доцент, кафедра уголовного процесса, Кубанский государственный университет,

г. Краснодар, Россия

\section{Получена: 11.06.2018}

Для цитирования: Немыка А.А., Сытина А.В. Междисциплинарность и полифункциональность в системе понятий современной науки (на материале терминов социолингвистики, социологии и лингвистики). Историческая и социально-образовательная мысль. 2018. Том. 10. № 3-2 . c.10-3/2-120-124. doi: 10.17748/2075-9908-2018-10-3/2-10-3/2-120-124.

\section{Information about the authors:}

Anna A. Nemyka, Doctor of Philological Sciences, Associate Professor, Department of Russian Language as Foreign, Kuban State University,

Krasnodar, Russia

annemyka@yandex.ru

Alla V. Sytina, Candidate of Philological Sciences, Associate Professor, Criminal Procedure Department, Kuban State University,

Krasnodar, Russia

Received: 11.06 .2018

For citation: Nemyka A.A., Sytina A.V. Interdisciplinarity and polyfunctionality in the system of concepts of modern science (based on the terms of sociolinguistics, sociology, and linguistics). Historical and Social-Educational Idea. 2018. Vol. 10. no.3-2. Pp. 10-3/2-120-124.

doi: $\quad 10.17748 / 2075-9908-2018-10-3 / 2-10-3 / 2-120-124$. (in Russ) 